Original Research Paper

\title{
Integration of Human Factor in Design Ergonomics: Example of a High Speed Train Cabin Design
}

\author{
Hajar El M'hadi and A. Cherkaoui \\ Mohamed V University, Ecole Mohammadia d'ingénieurs «EMI», Rabat, Morocco
}

Article history

Received: 28-11-2016

Revised: 20-12-2016

Accepted: 21-03-2017

Corresponding Author:

Hajar El M'hadi

Mohamed V University, Ecole

Mohammadia d'ingénieurs «

EMI », Rabat, Morocco

Email: hajar.mhadi@gmail.com

\begin{abstract}
The development of new technologies and technical progress has accelerated man/machine substitution. Work is disappearing in its human form. This technical progress has not avoided certain catastrophes occurring. These major disasters, both for man and for the environment, took place where reliability was at its highest level. The responsibility of the operator, of the human, the weak point in these systems, is of course quickly pointed out. Human error is thus incriminated. Of course, we do not speak of the accidents that have been avoided because of the intelligence of the operators. For us, the "key of success" of technical progress lies primarily in the adequacy between the performance of the new system, of the new product, etc and those who have to control it. Systems, products, etc, should not be reduced to their technical characteristics alone; they also have to integrate the human dimension. Ergonomics, although not being the only discipline concerned by the necessary change, can contribute greatly. In this context this paper presents an example of the contribution of ergonomics to a design project, where the ergonomist placed man at the centre of the design process. This project concerns the design of the driver's cab of the future TGV (high speed train). The approach requires a detailed analysis of the work activity, namely driving, which has both directed the design process and promoted the co-operation and collaboration between those involved in the design.
\end{abstract}

Keywords: Design Ergonomics, Product Design, Simulation, High Speed Train, Cabin, Humans Factor

\section{Introduction}

As Rifkin recalls in his book "The End of Work" (Rifkin, 1996), civilization, since its inception, has largely structured around the concept of work. Work has always been present in everyday life. Today, for the first time, work is often, if not systematically, eliminated, in its human form, from the process of production.

Indeed, since the early 1980s, bosses and company executives have chosen, for reasons of productivity, competitiveness, to bet on machines. Thus, with the advances in automation, a decoupling has been created between the growths of employment. The development of new technologies has led to an acceleration of male/machine substitution. Loss thus for the man of his trade, of his function, in the end of his expertise. Industrial technologies are supplanting, on the one hand, human labor. On the other hand, investment removes the need for skilled traditional jobs and creates new highly skilled jobs that are often vacant due to a lack of skilled personnel. However, this technical progress has not prevented certain major catastrophes from occurring. These great catastrophes have also taken place, where reliability is at its highest level, where safety has never been better, as Amalberti reminds us (Amalberti, 1995).

Of course, we do not talk about catastrophes avoided thanks to the intelligence or the presence of the human operator's mind, using his experience. Indeed, placed in a degraded situation of technical failure, the operator reexamines its main task by putting all its know-how and all its capacity of reasoning to adapt to this new situation. Thus, as emphasized by many works, unlike the machine, man knows how to interpret, estimate, make judgments and make decisions in order to provide an appropriate response to specific conditions, in time and place.

For us, only an interdisciplinary approach, combining the human sciences and the engineering sciences, can be able to give an answer to the challenge 
posed and a better consideration of human factors in the design process. The key to the success of technical progress lies in the adequacy of the performance of the new system, the new product... and those who will lead it. The product must not be limited to its technical characteristics; it must also integrate the human dimension. Knowledge of man and his behaviors must be at the heart of the design process, as soon as the needs are analyzed and continue throughout the design process (Sagot et al., 2003).

Therefore, ergonomics can make a large contribution. It is in this context that this article proposes to describe the ergonomic approach that has been implemented in the design of the driving cabin of future high-speed trains (TGV). The approach described here emphasizes the fine analysis of the work activity: Current and future driving activity, which has really enabled the ergonomist to advise the designer on the expectations and needs of future users.

\section{The Example of Integration of a Human Factor Engineering}

\section{The Context of the Study}

The opening of borders, the growing success and interest in high-speed travel throughout the world and the desire to maintain its leadership role in the field of high-speed rail ... have contributed to That Alstom propose to the public authorities a research and development program about high-speed trains.

These trains move at speeds of around $350 \mathrm{~km} / \mathrm{h}$. For such performance, power, aerodynamics, comfort and safety will still have to progress. They should allow drivers to meet the requirements of their duties in propecious conditions to their health, comfort, safety and passengers.

\section{Methodology}

We will start by analyzing the existing activity of driving, by elaborating a complete ergonomic diagnosis of the existing products: TGV Paris-South-East (noted TGV PSE) and TGV Atlantique (TGV A). This detailed analysis of the existing activity will allow to delineate the possible forms of future activity in order to provide a wider assessment of the consequences of their design choice to all the actors.

Therefore, in order to have a precise knowledge of the driving activity, the following methods and analyzes were used:

- Observations and analyzes from video recordings, carried out in the cabin, to collect actions and communications

- Verbalizations based on these same films and verbalizations by scenarios and questionnaires, where the speech of the driver was essential to fully understand his actions

Observations were obtained from 12 videotaped accompaniments. 6 drivers ( 3 for the TGV PSE and 3 for the TGV A) agreed to be registered during two journeys. During these journeys, four cameras were placed in the driver's cabin allowing simultaneous recording of the external environment (railway and signaling), his face (appreciation of direction, look), gestural postures of the driver and finally of the tachometer and its close zone.

The analysis of the data concerning the description of human behavior in driving situations was facilitated by the compression of the four video tapes into a single band and by the use of computer software KRONOS, a software that help in the collection and the systematic analysis of observation data (Kerguelen, 1986).

\section{Ascertainments}

From the films we found two things:

The possible quantification of certain activities (visual, gestural, postural) of the drivers according to the type of line, the situations of driving and the TGV. Drivers spend an average of $85 \%$ of their driving time watching the outside environment, specifically the track. We also note that drivers collect information on the desk, mainly on the tachometer or cab signal but also on the track record, voltmeters and ammeters. This information allows them to locate, to diagnose, to define strategies and especially to be able to anticipate

The identification of important inter-individual differences in the realization of the main speed control task, concerning the use of the Imposed Speed system (IS). The IS is a driving aid allowing to respect the speed limit, it acts as a stop and its use is more or less appreciated. Thus, all the drivers making the journeys on the TGV A never use this method of driving, unlike those of the TGV PSE which use it between 93 and $100 \%$ of the time on the whole route. For them, this "automatic" method of conduct generates different actions.

Thus, drivers who do not use the IS mode will have to use the traction control brake more. On the other hand, other drivers, using the IS, will often have to deal with the setting of the imposed speed, which often changes throughout the journey. As for the braking mode used, the latter also depends on the use or not of the IS, but also on the "style" of driving that driver look for according to the situations of driving encountered: Work, delay, bad Meteorological conditions...

The drivers of the TGV PSE defend the use of the IS because it allows them not to exceed the authorized speeds especially on the slopes. Indeed, the profile of the Paris-South-East lines being much more rugged, the drivers of the TGV PSE recognize using the IS to comply more easily with driving instructions. On the 
other hand, the TGV A drivers prefer to drive manually, but they mention using it in bad weather conditions (fog, rain ...), tiredness and less good line knowledge.

\section{Results}

The verbalizations made it possible to approach the activity of regulation of the speed from the angle of two important aspects that are the knowledge of lines and the strategies of expert regulation.

Thus, the knowledge of lines for drivers remains absolutely indispensable for their driving activities. Without this knowledge, drivers are obliged to use other modes of operation and other driving strategies that appear less efficient. The drivers integrate this knowledge of lines at the same time formal: Signaling, limit speeds ... and informal: Tunnels, bridges, dwellings ... in order to anticipate being able to regulate the speed and respect the time constraints. The assumption of line knowledge's organization in a linear format, according to the progress of the journeys, was defended and retained by the project group. This hypothesis constitutes a valid support for the information in the cabin compatible with the representations of conductors.

These results of driving activity's analyzearticulated with the technical and social factors to which drivers are confronted-made it possible to clearly identify the sources of variability that can generate incidents (Pinsky and Theureau, 1985), to highlight the theoretical shortcomings, the inadequacy of certain tools, the possible dysfunctions, their causes and their consequences. It was on the basis of this knowledge that it was possible to approach the field of desirable future activities in terms of safety, health, comfort and efficiency.

\section{Solutions}

These analyzes yielded a particularly valuable set of results, which helped the designer to develop his first design orientations. These guidelines resulted in the drawing up of a set of specifications in which we were able to elaborate a set of general and specific recommendations, concerning in particular:

- The main speed control interface (referred to as the HMI: Man-machine interface), the latter combining, in particular, the basic information requirements of the train (actual speed of the train, speed imposed, maximum speed allowed according to type of Line and signaling ...)

- The design and the integration of new control devices, necessary for the speed control spot

We will concentrate, in the following part, on this HMI of speed's regulation. The proposed solutions were studied in two steps:

\section{Preliminary Step: Definition of Preconcepts}

Dedicated to finding solutions, this stage consists in the development of scenarios designed to reconstitute fictitious but realistic activity situations, in accordance with the definition of the field of desirable future activities. The staging of scenarios from the simulation allows the ergonomist to guide the designer in his technical choices. This theoretical simulation remains a highly efficient prospective method (Maline, 1994). It makes it possible to understand the situations in which the operators will find themselves and thus to specify the possible consequences on their safety, health and comfort, consequences that would result from technical and organizational choices.

The support of these analyzes remains the Plan, with the emergence of software in Computer-Aided Design (CAD): The virtual model. The latter makes it possible to share information respecting to the business views. Thus, these approximate models in CAD will constitute the support that will help to select the best pre-concepts.

As part of the future TGV driving position, during the preliminary design phase, several HMI preconcepts related to speed regulation were proposed by the project group, based on the specifications and the definition of desirable's scope of future activities. This HMI is divided into two parts:

- A material part: The traction-braking control

- A software part: Corresponding to the information associated with it

Several of these pre-concepts were first the subject of virtual models, on which theoretical simulations could be conducted allowing scenarios to be reenacted restoring certain conditions for the exercise of desirable future activities.

Two pre-HMI concepts were retained by the project group, validated by the drivers. These pre-concepts are then the subject of interactive physical models, thanks to software of rapid prototyping (software VAPS) of which is once the Interface is realized in the environment, it is possible to generate the corresponding operational prototype, on any type of machine.

We were able to realize an "Assessment system" which regrouped all the devices relating to speed control (traction control braking associated with the visual assistance interface for driving, audible alarm ...) Visual environment of the track, sound environment cabin ..., this evaluation platform (Fig. 1) was equipped with several computers to reproduce the actual behavior of a TGV train, which enabled us to realize, in the presence of drivers, Simulations in view to evaluate, to validate the two preconcepts of HMI proposed. 


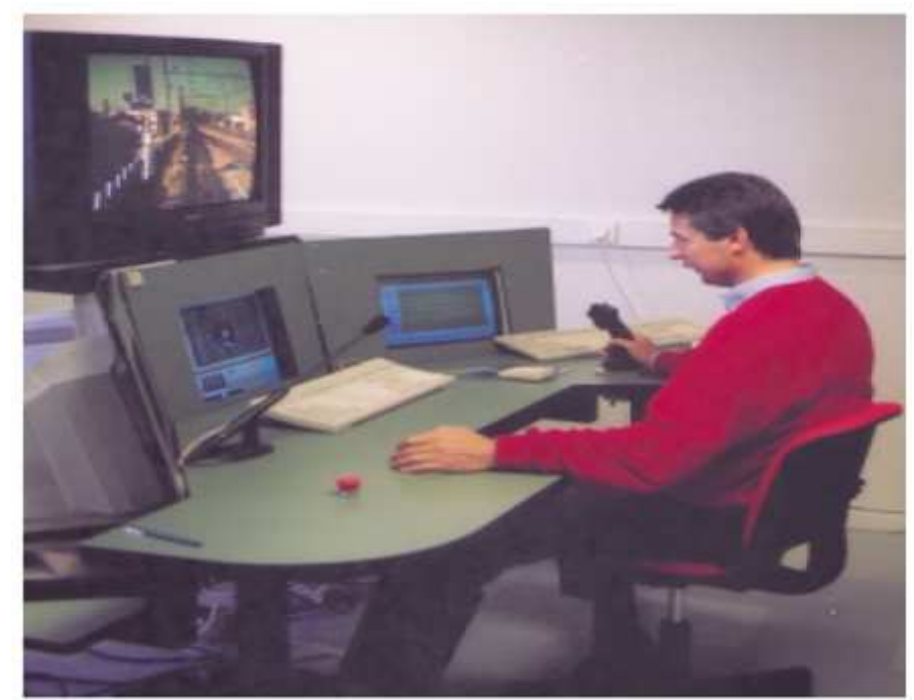

Fig. 1. Assessment system to study and validate the different HMI preconcepts retained

A privileged place was given to the drivers, thus leading to the definition of a concept of HMI linked to the regulation of speed, representing not the only solution, but the acceptable solution that we will Study during the design phase that followed.

\section{Detailed Step: Validation of the Prototype}

It is a question of going from an interactive model that demonstrates the feasibility, to a prototype product. This prototype product validates the expectations of the specifications and the set of ergonomic recommendations.

The original concept of the HMI for speed regulation lies in its design philosophy seeking to provide, on the basis of the field study, three types of information to drivers, namely:

- What it should do, for example, limited speed according to geographical location "the prescribed"

- What he does, that is, what he asks the machine to "the requested"

- What the machine achieves as a function of its functional state "the realized"

Thus, the driver can detect at any moment a difference between what he asks for and what is achieved, to investigate the causes of these deviations and to react accordingly. The intended aim of this interface's design was the need to provide the driver, on the basis of the study of existing driving activity, $a$ system of anticipatory assistance.

Thanks to the presentation of the discrepancies between the "prescribed", "requested" and "performed" provided by the interface, drivers have indicators that play the role of predictor, enabling early decision- making, made indispensable by the time of inertia of the rolling equipment reactions.

Figure 2 and 3 show the observed deviations between prescribed and reel speed with two drivers (a high speed novice and expert) during an imposed type scenario carried out on a simulator.

It can be seen, as shown in Fig. 2 and 3, that the conductors studied respect the "prescribed" well and that the deviations obtained between prescribed speed and actual speed are very low, taking into account:

- The severity of driving scenarios imposed

- Performance of rolling equipment: Inertia of the train ...,

- And the objectives seeking by the drivers themselves (comfort of the passengers, preservation of the equipment, ...)

These results, obtained under special conditions - if not exceptional, because the tested drivers do not know the lines and the rolling equipment they were going to use-confirmed the relevance of the HMI developed and thus confirmed the interest To have a driving aid. It should be remembered that, in general, in all sectors of activity, the need to design aids for anticipation is often put forward, especially in process control situations (Crossman et al., 1974).

There is widespread agreement that the human operator's information processing capabilities are limited. Since the single-channel theory, based on the assumption that the perceived information is serially processed by a single channel, some authors such as Wickens (1984) have introduced the idea of a multi-resource information processing system, Headed by a sort of supervisor, who would distribute these resources on a particular task according to the objectives of the subject. 


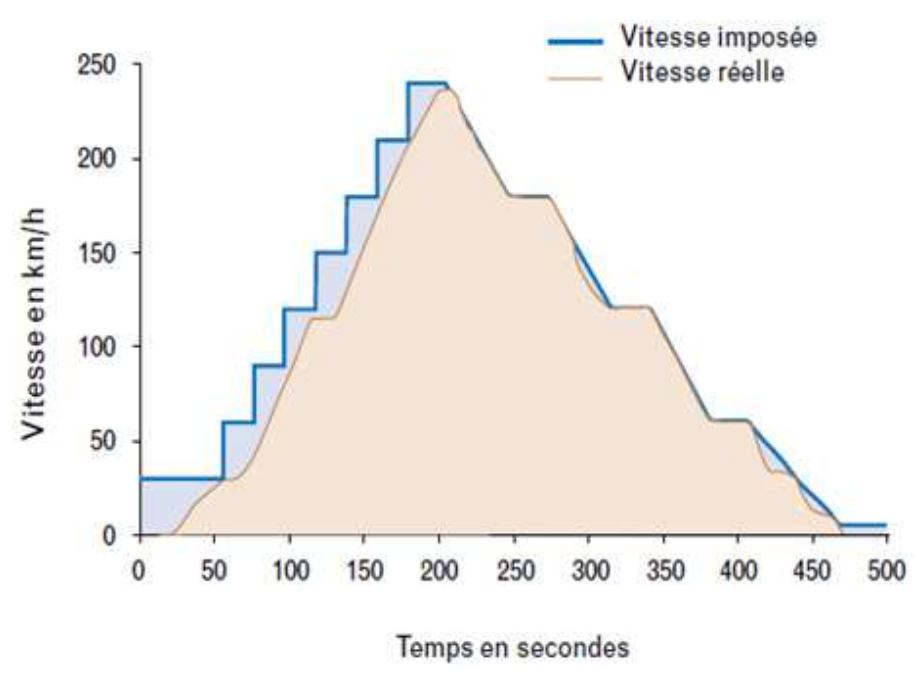

Fig. 2. Curves showing the real and compulsory speed of the train obtained with a novice driver during an imposed type scenario

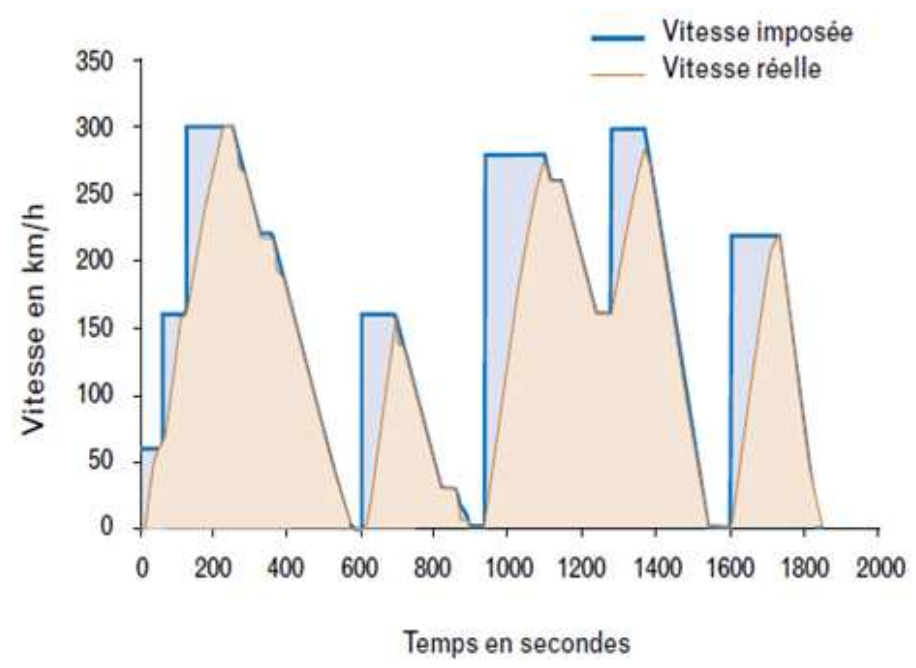

Fig. 3. Curves showing the real and compulsory speed of the train obtained with an expert driver during an imposed type scenario

This approach of attentional capacities seems to be well suited to the situation of train driving. The driver is obliged to prioritize the processing of the information in accordance with the goals that evolve according to the time and the conditions of the task's realization. This implies that the train management activity requires for drivers to share their attention and that the design of the new devices must take into account the operator's processing capabilities.

Based on this knowledge of actual driving activity, we were able to prototype a HMI linked to speed regulation, test it by stimulating certain exercise conditions of desirable future activities on a simulation platform, Validate and optimize it in order to design a technical, ergonomic and economic solution. Certain problems that had not appeared in previous phases, have been identified and corrected, integrating the business views.
Finally, it is necessary to emphasize that in the detailed studies, the "realistic conditions" of ergonomic tests that we have just mentioned, can in no way replace real conditions, where new Difficulties and new functional needs of drivers may appear. Thus, it is essential, for the prototype HMI we have just studied, that it be tested against real situations, in order to carry out the last validations. An ergonomic evaluation will be carried out on the prototype cabin, which should be installed on a test set.

\section{Discussion}

The proposed article presented an example of the contribution of ergonomics in a project of designing new product, concerning the design of the future TGV driving position, the ergonomist is described as a real partner, a real actor, a Co-designer, who, by placing the 
drivers at the center of the approach, allowed the specificity of the "human factor" to fit well into the design process.

The approach showed how the results of the analysis of the driving activity were essential to guide the design process and to encourage the cooperation of the actorstrades. Thus, through analysis of the activity, the ergonomist was able to federate all the players, not around the technical performance of the product under development, but around drivers, as future operators.

The ergonomist was able to advise the developer, by giving him the tools to investigate, test platform in preliminary studies, study simulator and design in detailed studies. Means to take into account the analysis of current and future driving activity in design decisions.

Drivers have thus played a central role in the understanding and formalization of their activity by the ergonomist. Particularly valuable were their participation in the various assessment tests, in which the ergonomist use imposed driving scenarios and scenarios of certain conditions for the exercise of desirable future activities. This participation made it possible to integrate their point of view in the design of the future technical systems, so that they can represent a real help to the driving activity.

Concerning the described contribution of the ergonomist in the design process, it should be pointed out that this contribution, which rather places the ergonomist as a companion of the design process. In this case, the ergonomist positions itself as revealing the synergies necessary to develop and, mediator between project manager and project manager. In both cases, regardless of the approach used, which often depends on the training provided by the workers (cognitive psychology, work psychology, occupational medicine, engineering, etc.), ergonomics is a safety factor. Health, efficiency through the implementation of all human capacities and innovation.

\section{Conclusion}

This paper presents an example of the contribution of ergonomics to a design project, where the ergonomist placed man at the centre of the design process. This project concerns the design of the driver's cab of the future TGV (high speed train). The approach requires a detailed analysis of the work activity, namely driving, which has both directed the design process and promoted the co-operation and collaboration between those involved in the design.

The approach showed how the results of the analysis of the driving activity were essential to guide the design process and to encourage the cooperation of the actors-trades. Thus, through analysis of the activity, the ergonomist was able to federate all the players, not around the technical performance of the product under development, but around drivers, as future operators.

\section{Acknowledgment}

The authors gratefully acknowledge the International Institute of Health and Security for providing the Information of the topic.

\section{Author's Contributions}

Hajar El M'hadi: Makes all the research to get information about the topic.

A. Cherkaoui: Assured a good frame of this work and validated the contents.

\section{Ethics}

This article contains unpublished material. No ethical issues involved.

\section{References}

Amalberti, R., 1995. Paradoxes de la sécurité des grands systèmes à risques, le cas de l'aéronautique. Performances Humaines et Techniques, 78: 45-55.

Crossman, E.R., J.E. Cooke and R.J. Beishon, 1974. Visual Attention and the Sampling of Displayed Information in Process Control. In: The Human Operator in Process Control, Edwards, E. and F.P. Lees, (Eds.), Taylor and Francis, Londres, pp: 25-50.

Kerguelen, A., 1986. L'observation Systématique en Ergonomie: Elaboration d'un Logiciel d'aide au Recueil et à L'analyse des Données. CNAM, Mémoire présenté en vue d'obtenir le Diplôme d'ergonomiste, Paris, pp: 64.

Maline, J., 1994. Simuler le travail: Une aide à la conduite de projet. ANACT, Paris, pp: 156.

Pinsky, L. and J. Theureau, 1985. Signification et Action dans la Conduite de Systèmes Automatisés de Production Séquentielle. CNAM, Laboratoire d'Ergonomie et de Neurophysiologie du Travail, Rapport $n^{\circ} 83$, Paris.

Rifkin, J., 1996. La Fin du Travail. 1st Edn., Editions la Découverte, Paris, pp: 435.

Sagot, J.C., V. Gouin and S. Gomes, 2003. Ergonomics in product design: Safety factor. Safety Sci. J., 41: 137-154.

Wickens, C.D., 1984. Processing Resources in Attention. In: Varieties of Attention, Parasuraman, R. and D.R. Davies (Eds.), Academic Press, Londres, pp: 63-98. 